\title{
INTRODUCCIÓN
}

Uno de los problemas más arduos de la enseñanza-aprendizaje del español como lengua extranjera (ELE), principalmente a hablantes de lenguas no románicas, es el subsistema de las formas verbal es del pasado, y en especial la distinción aspectual perfectiva-imperfectiva que se real iza en los tiempos pretérito y copretérito. ${ }^{1}$

Los programas y los libros de texto de ELE abordan la enseñanza de estas formas, general mente a nivel de la oración y no del discurso. Las explicaciones son insuficientes y muchas veces confusas para los al umnos. Obsérvense las siguientes explicaciones tomadas de manuales de enseñanza de ELE, presentados por M. J urado: ${ }^{2}$

El imperfecto se usa para expresar:

- Descripción de personas, cosas o situaciones:

(1) Hacía bastante calor.

- Profesión u ocupación permanente en el pasado:

(2) Mi abuelo era maestro.

- Sin embargo es posible:

(3) Hizo bastante calor.

(4) Mi abuelo fue maestro.

Un recurso que se usa con mucha frecuencia para explicar la distinción de estas formas es relacionar el uso del pretérito y copretérito con determinados tipos de adverbios. Por ejemplo, el pretérito, según al gunos manuales de enseñanza ${ }^{3}$ utiliza los adverbios y las frases: ayer, anoche, la semana pasada, el otro día, hace un mes, el año pasado, etcétera, mientras que el copretérito utiliza Ios adverbios y las frases: antes, nunca, siempre, todos los días, a veces, nunca, casi siempre, frecuentemente, cada año, etcétera.
1 M. Gutiérrez Araus, "Formas temporales del pasado en indicativo", en Cuadernos de lengua española, p. 9.

2 Vid. Martha Jurado Salinas, "La diferencia pretérito/copretérito. Una explicación basada en los conceptos de 'aspecto' y 'tipo de situaciones' y su aplicación a la enseñanza del español a extranjeros", en Decires, núm. 1, vol. 1.

3 Idem. 
Como se observa en los siguientes ejemplos, el uso de determinados adverbios y frases adverbiales no siempre son exclusivos de una u otra forma verbal:

(5) Daniela viajó/ viajaba a Mérida cada año hasta que murió su abuela.

(6) Siempre visité/ visitaba a mis abuel os con gran alegría.

(7) Anoche tuve/ tenía mucha fiebre.

La enseñanza de maneraaislada, a nivel oracional, dela distinción entre las dosformas del pasado presentada en los ejemplos anteriores, resulta insuficiente ya que no le aportaal al umno un conocimiento del que podrá val erse en una situación de comunicación real, cuando necesite relatar una historia o contar una experiencia. En el siguiente ejemplo se puede observar el uso de estas formas en el contexto discursivo:

(8) El mes pasado, un lunes como a las once de la mañana, salía de mi casa cuando me encontrécon J uan, que fue mi maestro de español en la escuela secundaria. Fuimos a una cafetería y nos divertimos mucho recordando los viejos tiempos. Fue una experiencia inolvidable. A partir de ese momento, nos vimos todos los lunes para tomar un café hasta que regresó a su pueblo.

De acuerdo con las explicaciones mencionadas anteriormente, resultaría confuso para un alumno el uso de salía, del ejemplo anterior, después de una frase adverbial que indica un momento puntual: El mes pasado, un lunes como a las once de la mañana. En el contexto del discurso, la forma salíaindica una acción durativa que se realiza en el momento del encuentro de J uan y su maestro. I gualmente en la oración final, el uso de la forma nos vimos seguida de la frase adverbial todos los lunes, sería confusa para los al umnos si no se toma en cuenta la frase hasta que regresó desu pueblo, queen el contexto expresa un punto terminal de la acción referida. Las descripciones expresadas en pretérito: fue mi maestro y fue una experiencia inolvidable, seentiende dentro del contexto del discurso como eval uaciones o comentarios referidos al pasado y que son situaciones completadas desde el presente de la enunciación. 
La distinción aspectual que se realiza en las formas del pretérito y copretérito, y su uso para la función de narrar, sól o pueden ser cabal mente comprendidos en el contexto del discurso narrativo. Sin embargo, la condición generalizada es que la selección y gradación de los contenidos de los programas, así como los libros de texto, no abordan la enseñanza de esta morfología considerando la relación de las formas con su función en la narración.

Por otro lado, no se tiene en cuenta que su aprendizaje requiere de un proceso de adquisición queva desde los niveles principiantes a los nivel es avanzados de enseñanza de la lengua. En el campo de la investigación en adquisición de segundas lenguas, el desarrollo de la morfología verbal del pasado en español ha sido abordado ampliamente y existen una serie de hi pótesis, provenientes de estudios empíricos, que proponen una secuencia de adquisición en el interlenguaje de los alumnos. Estos estudios son relativamente recientes y todavía no se ven, o son muy escasas, las aplicaciones de esta información en los libros de texto para la enseñanza del ELE.

En estetrabajo presentaréunadistinción del pretérito/ copretérito con un enfoque, que va mas allá de los límites de la oración, y explica el uso de estas formas en la configuración y estructuración del discurso narrativo. Por otro lado, explicaré brevemente las características de la secuencia de adquisición de la morfol ogía verbal del pasado en español, de acuerdo con las investigaciones sobre este tema. Finalmente, con base en los argumentos aquí presentados, propondréuna graduación de contenidos, tareas y ejercicios que servirán para la enseñanza-aprendizaje del pasado en español en el contexto discursivo-narrativo, desde los niveles principiantes a los nivel es avanzados ELE.

TIEMPO Y ASPECTO EN EL DISCURSO NARRATIVO EN ESPAÑOL

En las últimas décadas, se ha pasado de un enfoque paradigmático, que explica los significados temporal es-aspectual es distintivos de cada una de las formas verbal es en el sistema, a un enfoque semántico-funcional que va más al lá de los límites oracionales, dentro de los que 
4 F. Colombo, El subsistema de los Tiempos Pasados de Indicativo en Español. Semántica y Sintaxis, p. 76.

5 Tiempo verbal: expresa la idea general de la localización de la acción en el tiempo,

básicamente por su orientación con relación al momento del habla o en un sentido más amplio por el

"aquí" y "ahora" del hablante. (Vid. Maslow, Contrastive Studies in verbal Aspect).

6 Aspecto verbal: diferentes formas de presentar la constitución temporal interna de una situación. (Vid.Comri, Aspect).

7 Benveniste, cit. por D. Maingueneau, Introducción a los métodos de análisis del discurso, p. 118.

8 Vid. H. Weinrich, Estructura y función de los tiempos en el lenguaje.

9 Ibid., p. 99.

tradicional mente se habían considerado las categorías verbales, e intenta explicar las estrategias comunicativasquesesiguen parala configuración y estructuración del discurso. ${ }^{4}$

En general, estos acercamientos reconocen las nociones del tiempo ${ }^{5}$ aspecto verbal ${ }^{6} \mathrm{como}$ puntos de partida para el análisis de los tiempos gramaticales, pero advierten su insuficiencia para dar cuenta del empleo de las formas verbales en la producción e interpretación del discurso.

\section{Niveles narrativos}

Los tiempos verbales no se ordenan en un mismo nivel, ya que además del momento de la enunciación (nivel metanarrativo) que es el primer referente temporal, existe el de la narración (nivel narrativo). Muchos autores han establecido esta distinción entre tiempos narrativos y tiempos coloquiales.

Benveniste sostiene que los tiempos del verbo (francés) no se emplean como miembros de un sistema único, sino que se distribuyen en dos sistemas distintos y complementarios disponibles para cada hablante y que corresponden a dos planos de enunciación diferentes: la historia y el discurso. ${ }^{7}$ Weinrich ${ }^{8}$ explica el funcionamiento de las formas verbal es en su uso discursivo-textual en su libro Estructura y función de los tiempos en el lenguajerecurriendo a lo que él denomina "actitud" del hablante. Según este autor podemos comportarnos frente al mundo narrándol o o comentándolo; para una u otra "actitud" del hablante contamos con dos grupos temporales: uno que se organiza en torno al presente como 'tiempo cero" del mundo comentado y otro, que tieneal pretérito y al imperfecto como "tiempos cero" del mundo narrado. ${ }^{9} \mathrm{Al}$ interior de cada grupo, las formas se articuIan para expresar la perspectiva, ya sea retrospectiva o prospectiva de los eventos que tienen como referencia temporal los tiempos cero de cada grupo. Al contar una historia el hablante construye un "mundo narrado" (story world), en el cual un determinado número de entidades actúan e interactúan unas con otras en una locación de- 
finida y por un período de tiempo determinado. Por otro lado, Ias narraciones pueden estar dentro de una conversación. El mundo narrado, como un mundo independiente, puede involucrar expresiones de tiempo que se proyectan hacia afuera de este mundo y que se relacionan con la situación de conversación. ${ }^{10}$

\section{Los planos de la narración}

Weinrich"1 explica la oposición de pretérito e imperfecto con base en su función de dar "relieve" a la narración, es decir de destacar ciertos contenidos de comunicación de otros y así establecer una diferencia de planos en la narración. La función del relieve narrativo ha tenido repercusión en la posterior distinción de planos de la narración: foreground (primer plano) y background (plano de fondo).

Esta distinción en planos, con respecto al tipo de información que se presenta en el discurso narrativo, proviene de la diferenciación más simple y primitiva de la organización perceptual: la relación de figura y fondo. Implica una relación entre la percepción visual y la organización gramatical. ${ }^{12}$

La investigación lingüística sugiere que esta distinción en planos tiene características universales. Hopper ${ }^{13}$ observa que los usuarios competentes de una lengua marcan una ruta principal en la narración y desvían de diferentes maneras aquellas partes de la narración que no son estrictamente relevantes para esa ruta. Se puede afirmar, según este autor, que en la mayoría de las lenguas existe al gún tipo de recurso morfológico que cumple la función de distinguir los elementos secuenciados del primer plano y los elementos no secuenciados: las acciones en progreso (on going processes), los eventos repetidos y los estados del plano de fondo del discurso.

\section{El primer plano de la narración}

Las características principales del primer plano pueden ser resumidas según Reinhart ${ }^{14}$ de acuerdo con el siguiente criterio temporal:
10 Vid. D. Schiffrin, Approaches to discourse.

11 Vid. H. Weinrich, op. cit.

12 Wallace, "Figure and Ground. The interrelationships of linguistic categories", en Hopper, Tense and Aspect, vol. 1, p. 213.

13 P. Hopper, "Aspect between discourse and grammar", en Hopper Paul, Tense and Aspect, vol 1., p. 239.

14 T. Reinhart, "Principles of gestalt perception in the temporal organization of narrative texts", en Linguistics, núm. 22, p. 801. 
15 D. Schiffrin, Approaches to discourse, p. 47.

16 K. Bardovi-Harlig, Tense and aspect in second language acquisition: Form, meaning and use, p. 282.
Narratividad o continuidad temporal: Sólo las unidades narrativas, es decir las unidades cuyo orden siguen el mismo orden de los eventos que reportan, pueden servir para el primer plano.

Puntualidad: Las unidades que reportan eventos puntuales pueden servir más fácil mente como primer plano que las unidades que reportan eventos durativos, repetidos o habituales.

Completitud: El reporte de un evento completado puede servir más fácilmente para el primer plano que el reporte de un evento en progreso.

El primer plano de la narración lleva la línea histórica de los eventos. Para Hopper, en este plano se relatan los eventos que pertenecen al esquel eto estructural del discurso. El primer plano presenta los eventos en un orden secuencial y consiste en cláusulas que hacen avanzar los eventos en el tiempo. El punto de referencia temporal de cada evento del primer plano es entendido como sucesivo del evento que lo precede. El concepto de secuencialidad de las cláusulas del primer plano puedeser definido por la interpretación que se deriva del orden en que se presentan las cláusulas, "si un cambio en el orden de las cláusulas resulta en un cambio en la interpretación de lo que sucede en la narración, entonces estas cláusulas pertenecen al primer plano". ${ }^{15}$

En el siguiente ejemplo un cambio de orden en las cláusulas narrativas —en letra cursiva - representaría un cambio de la interpretación del relato.

(12) Pedro Páramo siguiómoviendo los labios, susurrando palabras. Después cerróla boca y entreabriólos ojos, en los que se reflejóla débil claridad del amanecer.

J uan Rulfo, Pedro Páramo.

El plano defondo de la narración

A diferencia del primer plano, que tiene una única función, el plano de fondo - background-tiene, según Bardovi-Harlig, ${ }^{16}$ muchas funciones individual es, que de manera conjunta sirven al propósito de presentar el 
escenario, las condiciones en las que se desarrolla la trama de la acción narrativa del primer plano. En contraste con los eventos reportados en el primer plano que son presentados de manera secuenciada, los eventos del plano de fondo pueden estar fuera de la secuencia con respecto al primer plano y también con respecto a otros eventos del plano de fondo.

En el ejemplo 13, que se presenta a continuación, el evento que describe el escenario -amanecía-, que es durativo y simultáneo a los eventos del primer plano, puede cambiar su orden, con respecto a los eventos del primer plano, como se muestra en los ejemplos 13a y 13b sin que esto signifique una al teración de la historia.

(13) Pedro Páramo siguiómoviendo los labios, susurrando palabras. Después cerróla boca y entreabriólos ojos, en los que se reflejóla débil claridad del amanecer. Amanecía.

(13a) (Amanecía). Pedro Páramo siguió moviendo los labios, susurrandorrando palabras. Después cerróla boca y entreabriólos ojos, en los que sereflejóla débil claridad del amanecer.

(13b) Pedro Páramo siguió moviendo los labios, susurrando palabras. (Amanecía). Después cerróla boca y entreabrió los ojos, en los que se reflejó la débil claridad del amanecer.

El siguiente párrafo muestra parte de la morfología verbal que se puede encontrar en el plano de fondo (subrayado):

(14) J oséPalacios, su servidor más antiguo, lo encontró flotando en las aguas depurativas de la bañera, desnudo y con los ojos abiertos, y creyó que se había ahogado. Sabía que ése era uno de sus muchos modos de meditar, pero el estado de éxtasis en que yacía a la deriva parecía el de al guien que ya no era de estemundo. No se atrevióa acercarse, sino que lo llamó con voz sorda de acuerdo con la orden de despertarlo antes de las cinco para viajar a las primeras luces. El general emergió del hechizo, y vio en la penumbra...

García Márquez, El general en su laberinto. 
17 W. Labov, Language in the inner city: Studies in the Black English vernacular, p. 363.

18 Ibid., p. 366.
En el ejemplo 14 encontramos una secuencia narrativa en letra cursiva, cuyos eventos hacen avanzar el tiempo de la historia, queconstituyen el primer plano de lanarración. En el plano de fondo encontramos eventos simultáneos a loseventos del primer plano -la descripción de laforma en que yacía el general, por ejemplo-y eventos anteriores a los eventos del primer plano, como en: creyó que se había ahogado, donde el segundo evento es anterior al primero, que es su punto de referencia.

\section{La estructura narrativa de Labov}

Hay otras propuestas de análisis de la estructura narrativa, que no están formuladas con criterios temporal es. Nos interesa exponer en este trabajo la propuesta formulada por Labov, ${ }^{17}$ por la relación que existe entre sus categorías discursivas y la distribución del pretérito y copretérito del español. Los seis el ementos de su estructura narrativa son los siguientes:

1. Abstract

2. Orientation

3. Complicatingaction

4. Evaluation

5. Result or resolution

6. Coda

El "resumen" (abstract) encapsula el punto de la historia, da una versión completa (full account) dela misma. La parte de orientación identifica, de al guna manera, el tiempo, lugar, personas y sus actividades o la situación. Puede encontrarse en las primeras cláusulas narrativas, pero más comúnmente hay una sección de orientación que presenta un cuadro detallado de la situación. La parte de "complicación de la acción", es el esquel eto de la narración, "presenta el conflicto o el problema de la historia"; la "evaluación" es, para Labov, ${ }^{18}$ la sección que presenta los comentarios del autor; Labov distingue entre "evaluación externa", es la sección en que el narrador detiene la narración, se dirige al oyente y le dice al go sobrealgún punto y la eval uación "incrustada" (embedding of evaluation), en la que el narrador expresa un senti- 
miento o una emoción que pueden ser instantáneas o simultáneas con el tiempo de la acción, y no fuera de la narración. El "resultado" o la "resolución" es la conclusión de la narración y el el emento denominado "coda" muestra, general mente, el efecto de los eventos en el narrador; es una de las opciones que tiene el narrador para señalar el final del relato; tiene la propiedad de tender un puente entre el momento del tiempo que correspondeal final de la narración con el presente.

Siguiendo el esquema narrativo propuesto por Labov, Colombo ${ }^{19}$ señala una tendencia bastante generalizada del pretérito del español como forma verbal que expresa el "resumen". Asimismo, en pretérito se encuentran las oraciones propiamente narrativas, quellevan la secuencia de los hechos narrados, y la "resolución-coda", con la cual se da por concluido el relato.

El copretérito aparece como la forma típica de la sección de orientación. En ella se describen las circunstancias del lugar, tiempo, condiciones, características de los personajes y todo aquel lo que permite ambientar la trama del relato.

En las secciones de "complicación de la acción"y de "evaluación" pueden al ternar las formas del pretérito simple, del presente histórico y del imperfecto. En estas secciones, el imperfecto desempeña la función del segundo plano, describiendo características o condiciones específicas del acontecimiento relatado. ${ }^{20}$

SECUENCIA DE ADQUISICIÓN DEL PRETÉRITO Y COPRETÉRITO EN ESPAÑOL COMO L2

Numerosas investigaciones sobre la adquisi ción de la temporalidad en las lenguas muestran que la emergencia y desarrol lo de la morfol ogía verbal depende de distinciones aspectual es - H ipótesis del Aspecto-y de categorías funcional es de la organización del discurso - Hipótesis del Discurso.

La Hipótesis del Aspecto ${ }^{21}$ ha mostrado evidencias de una secuencia de adquisición en el desarrollo de la morfología verbal del pasado en las lenguas. La investigación referida a esta hi pótesis se realizó en diferentes len-
19 F. Colombo, "Tiempo, aspecto y funciones comunicativas", en Estudios de Lingüística Aplicada, p. 20.

20 lbid., p. 27.

21 Vid. R. Andersen, “Developmental sequences: The emergence of aspect marking in second language acquisition", en T. Huebner y C. Ferguson (eds.), Crosscurrents in second language acquisition and linguistic theories. 
22 Salaberry, "The development of past tense verbal morphology in classroom L2 Spanish", en Applied Linguistics, pp. 151-178.

23 Realizaciones: son eventos dinámicos, durativos y télicos. Son ejemplos de realizaciones: derretirse, secarse, escribir una carta, bailar un tango, etcétera.

24 Cumplimientos: son eventos dinámicos, télicos e instantáneos que implican un cambio de estado. Ejemplos: llegar, ganar la carrera, morir, etcétera.

25 Actividades: son situaciones de naturaleza dinámica y temporalmente ilimitadas. Ejemplos: caminar, cantar, jugar.

26 Estados: son situaciones carentes de dinamismo, homogéneas. Ejemplos: estar, tener, etcétera.

27 Vid. K. Bardovi- Harlig, Tense and aspect in second language acquisition: Form, meaning and use.

28 Ibid., p. 315. guas; en diferentes contextos de aprendizaje (formal y no formal); con diferentes procedimientos de recolección de datos: narrativas orales y escritas, ejercicios tipo cloze, tareas de contar historias a partir de imágenes, películas, etcétera; en estudios Iongitudinal es y transversales, etcétera. Un buen número de estudios teóricos y empíricos ha analizado esta propuesta en la adquisición del español como L2 (por ejemplo Robinson, Liskin Gasparro, Salaberry, ${ }^{22}$ ). A pesar de algunas discrepancias en las investigaciones, hay un acuerdo de los términos generales de esta hipótesis que sostiene lo siguiente:

- Los aprendices usan primero la marca perfectiva con eventos télicos (real izaciones ${ }^{23}$ y cumplimien$\operatorname{tos}^{24}$ ) y se extiende gradual mente a actividades ${ }^{25} y$ estados. ${ }^{26}$

- En lenguas con marca imperfectiva, el pasado imperfectivo aparece después del pasado perfectivo y se restringe primero a estados y actividades y después a eventos télicos (realizaciones y cumplimientos).

Otros estudios sobre adquisición de la temporal idad en las lenguas, que toman al discurso como marco de estudio, muestran que el desarrollo de la morfología de tiempo-aspecto, en el interlenguaje de los alumnos, está estrechamente relacionada con las funciones que estas formas expresan en el discurso. ${ }^{27}$ Las investigaciones relacionadas con la Hipótesis del Discurso son, en su gran mayoría, estudios cualitativos. Bardovi-Harlig, usa ambos marcos de análisis de los datos y llega a la conclusión que, lo que se hace evidente, con el soporte de las dos hipótesis, es la influencia conjunta de la clase aspectual y la estructura narrativa. Concluye Bardovi-Harligg que usar los verbos para construir el discurso, puede ser la única forma en que los aprendices puedan adquirir la expresión de tiempo-aspecto que caracteriza la lengua de los hablantes nativos. 
Existe una relación entre las categorías discursivas y la distribución de la morfología de tiempo-aspecto del pasado en español. Con base en esta relación y en la secuencia de adquisición de estas formas en el interlenguaje de los al umnos, se propone una tipología de textos narrativos, con diferentes grados de dificultad, para la enseñanza del contraste pretérito/ copretérito en español como segunda lengua. Esta tipología puede ser usada como textos de entrada (input) o como base para los ejercicios y actividades para la práctica y uso de estas formas en el salón de clases. Esta secuencia de textos está pensada como una guía básica de gradación de contenidos para el maestro y los diseñadores de materiales que se puede insertar en diferentes niveles de un programa de acuerdo con la estructura general del mismo. En orden creciente de dificultad de los textos, la tipología es la siguiente:

\section{Textos enfocados a la Secuencia de eventos/ Primer plano de la narración}

Textos narrativos con énfasis en el uso del pretérito para expresar los eventos secuenciados que hacen avanzar la historia, el primer plano narrativo:

J uan /legó al metro, bajólas escaleras, compró el boleto y entróal andén.

La característica de los eventos que conforman el primer plano, la secuencia de eventos que llevan Ia trama de la narración es la "telicidad" (delimitación de un punto final). Encontramos acciones télicas: puntual es (cumplimientos) como llegó, entróy durativas (realizaciones) como bajó las escaleras, compró el boleto. Son eventos que aparecen como acabados, completados y, por lo tanto, se usan con pretérito. 
En niveles principiantes, este tipo de textos propiciará el aprendizaje del pretérito en un estadio temprano de adquisición en el que los al umnos distinguen esta forma combinada con eventos télicos. Para este nivel, generalmente es necesario adaptar o simplificar los textos enfocados a relatar una secuencia de eventos.

Ejercicios sugeridos: ordenar eventos de una narración, inventar el final o el comienzo de una narración, etcétera.

\section{Textos enfocados a la descripción de personas, cosas, escenas y hábitos}

Textos con énfasis en el uso del copretérito para expresar descripciones y situaciones habituales en pasado. En este tipo de texto habrá preponderancia de estados y actividades. Los estados y las actividades (acciones durativas atélicas) se adquieren combinadas con el copretérito en una primera etapa de adquisición. Este tipo de texto, puede introducir el uso del copretérito de manera independiente o como introducción de una narración. Muchos textos que describen personas o lugares en el pasado cumple con estos requerimientos:

J uan era un hombre solitario, tenía unos 40 años, vivía en un vecindario al norte de la ciudad y trabajaba como velador en un edificio del centro.

Cuidabal os cuatro pisos de oficinas, de martesa domingo, de 8 de la noche a siete de la mañana. Por las noches, recorría el edificio, bajaba y subía escaleras y revisaba puertas y ventanas de cada oficina.

El texto anterior expresa situaciones habituales. En una narración puede estar al comienzo de la misma, con la función de describir u orientar sobre los personajes y circunstancias de la historia. Las características de los eventos son la "estatividad" y la "duratividad". En estos textos encontramos una mayor frecuencia de estados (era, tenía, vivía) y actividades - acciones durativas- (cuidaba los pisos, recorría el edificio, etcétera). Son situaciones en las que no se precisa su inicio ni final, y por lo tanto se usan con copretérito. 
Ejercicios sugeridos: describir personas del pasado (ejemplo: mis amigos de la infancia); describir costumbres de antes y de ahora (ejemplo: los juegos infantiles) para contrastar este uso con el presente.

3. Textos enfocados a narraciones que incluyan:

Secuencia de eventos/ Primer plano

de la narración (pretérito).

Escenario/ Orientación/ plano de fondo

de narración (copretérito)

Textos narrativos que contengan una sección de "orientación", con descripción de los personajes, escenarios y eventos habituales (idem a los textos 2) y una secuencia narrativa con el uso del pretérito para el primer plano de la narración y descripciones del plano defondo en copretérito:

J uan era un hombre solitario, tenía unos 40 años, vivíaen un vecindario al norte de la ciudad y trabajabacomo velador en un edificio del centro.

Ese día, J uan llegóal metro, bajólas escaleras y entróal andén. Había mucha gente esperando el tren. Un niño /lorabaen los brazos de su mamá, estabainquieto por el calor y la falta deaire. Su mamálo mecía y le hablaba dulcemente para calmarlo.

En el ejemplo del texto anterior hay un primer plano en pretérito con eventos télicos; en el plano de fondo, encontramos la descripción del escenario en copretérito, combinado con estados y actividades, que son durativos y simultáneos a los eventos que ll evan la trama de la historia. Las combinaciones del pretérito y copretérito con estos tipos de verbos son las más frecuentes para expresar las funciones narrativas del primer plano y plano de fondo de las narraciones.

Con este tipo de textos se conjunta el uso de pretérito y copretérito para las funciones narrativas propias de estas formas y que están en los primeros estadios de adquisición de lo alumnos que no son hablantes nativos del español. 
Ejercicios sugeridos: identificar la parte descriptiva de la narrativa, ordenar las frases que conforman la trama de la narración.

4. Textos que expresen las funciones de los planos narrativos e incluyan eventos y acciones anteriores o posteriores a la línea temporal de la secuencia narrativa con el uso de antecopretérito y pospretérito.

Una vez sistematizado los usos de pretérito y copretérito para las distintas funciones narrativas puede incluirse otra morfología verbal del plano de fondo como por ejemplo el antecopretérito y el pospretérito. Esta morfología aparecerá en el contexto discursivo con referencia a eventos del plano de fondo o del primer plano de la narración para expresar una perspectiva retrospectiva a estos eventos, en el caso del antecopretérito, o una perspectiva prospectiva, en el caso del pospretérito:

J uan vivía en un cuarto de dos por dos, que había heredado de un amigo, y estaba al norte de la ciudad...

Vio a la muchacha que se tambal eaba y tuvo el presentimiento de que al go grave sucedería...

Ejercicios sugeridos: ordenar eventos, relacionar eventos anteriores o posteriores a la trama de la narración.

5. Textos narrativos que incluyan las funciones de los planos narrativos y las secciones de epílogo, resumen, evaluación; estas últimas con énfasis en el uso del pretérito como completado en el momento de la enunciación.

Textos narrativos que contengan las secciones de orientación, resumen, trama narrativa, evaluación, resolución y coda con la inclusión de todo tipo de verbos combinados con pretérito y copretérito. En esta etapa de la secuencia, se hará énfasis en el uso de pretérito con actividades y con estados para el primer plano, combinaciones que son 
poco frecuentes en los textos narrativos y que son las que más tardíamente adquieren ( pal abras subrayadas en el siguiente texto):

J uan entróal andén y se parójunto a una señora que llevaba un niño en brazos. Observó a su alrededor y en un momento vio a una muchacha con una expresión muy triste que se tambal eabacerca de la línea amarilla. J uan tuvo un presentimiento y rápidamente se dirigióhacia ella. En ese momento el tren Ilegaba la estación. J uan la tomó por el brazo y la muchacha comenzó a gritar.

En el texto anterior se incluye un estado con pretérito (tuvo un presentimiento) combinación que tiene la característica de imprimirle al estado un significado de ingreso al estado (puntual). Este tipo de combinaciones son las que más tardíamente se adquieren. También están en una etapa final de adquisición la combinación de actividades - acciones durativas/ atélicas-como en: observó a su alrededor.

La combinación de copretérito con eventos télicos, especial mente con eventos puntuales, que se adquiereal final de la secuencia aparece de manera esporádica en el plano de fondo (el tren llegaba).

En la misma etapa puede sistematizarse el uso del pretérito con estados en las secciones de "evaluación externa" "resumen" o "epílogo". Para estas funciones narrativas el pretérito puede aparecer con estados, fuera del eje temporal de la narración.

Ejemplo: Esa fuela peor tarde de su vida...

Ejercicio sugerido: identificar las partes de la narración: resumen, orientación, descripción de escenario, trama narrativa, epílogo.

Para que los al umnos puedan identificar los usos más difíciles - por ejemplo pretérito con estado para el epílogo del relato-, se pueden usar ejercicios en los que se contrasten estosusos con otrosya adquiridos - copretéritos con estados- para describir el escenario de la narración.

Ejemplos: Era una tarde luminosa cuando J uan salió de su casa rumbo a su trabajo...

Esa fuela peor tarde de su vida... 
29 "El héroe" es un cortometraje mexicano de animación dirigida por Carlos Carrera.

La tipol ogía propuesta en este trabajo, se puede encontrar en textos auténticos o bien se pueden elaborar o adaptar textos para las primeras etapas de adquisición. Los ejemplos presentados para cada uno de los niveles, forman parte de narraciones el aboradas por al umnos de diferentes nivel es del CEPE sobre el argumento del cortometraje "El héroe". ${ }^{29}$

En cada etapa se puede reforzar los usos que se van incluyendo con ejercicios, similares a los sugeridos, que permitan contrastar las diferentes formas y sus funciones narrativas.

Si ya existe un programa, con una secuencia diferente, estos contenidos se pueden impartir como parte de un curso complementario de narración para los alumnos de un nivel intermedio, ya que en este nivel pueden sistematizar el uso de la morfología del pasado, que vienen aprendiendo desde niveles básicos, dentro el contexto de la narración.

De acuerdo con mi experiencia, usar el metalenguaje referido al aspecto léxico no es recomendable en Ios niveles iniciales, y puede ser de utilidad la distinción entre acciones y estados desde los nivel es intermedios bajos; el uso de la terminología referida a las categorías y funciones narrativas como: "trama narrativa", "descripción del escenario", "orientación del escenario y de los personajes de la historia", "resumen de la historia" es útil para comprender las distintas partes de la narración y su relación con el uso de determinadas formas desde los niveles iniciales. El uso de la terminol ogía referida a los planos narrativos es de utilidad con niveles intermedios, cuando ya están sistematizados los usos del pretérito y copretérito para todas las funciones narrativas, como una actividad de reflexión sobre el lenguaje y su uso en el discurso, que ayuda a integrar el conocimiento que ya han adquirido.

\section{CONCLUSIÓN}

La forma de presentar y enseñar la morfología del pasado en español resulta confusa para los al umnos porque no tiene en cuenta el uso de las formas en su contexto dis- 
cursivo. Por otro lado, no se considera la secuencia de adquisición de estas formas, por la que pasan los alumnos en el desarrollo de su interlenguaje. La secuencia y gradación de los contenidos de los programas de español como L2, se hace de manera arbitraria o considerando ciertos contrastes que se ejercitan a nivel de la oración como se muestra en los contenidos de manuales de enseñanza.

La tipología de textos que aquí se presenta es una guía, para la gradación y secuencia de los contenidos de un programa, que pretende favorecer y propiciar la enseñanza-aprendizaje de estas formas con un input que sea másfácilmente comprendido, ya que acompaña el proceso natural de adquisición. Esta tipología se basa en una secuencia creciente de dificultad del texto con respecto a las formas que lo constituyen y las funciones que expresan dentro del discurso.

BIBLIOGRAFÍA

ANDERSEN, R., “Developmental sequences: The emergence of aspect marking in second language acquisition", en T. Huebner y C. Ferguson (eds.), Crosscurrents in second language acquisition and linguistic theories. Amsterdam, J ohn Benjamins Publishing Company, 1991.

BARDOVI-HARLIG, K., Tense and aspect in second language acquisition: Form, meaning and use. Oxford, Blackwell Publishers Inc., 2000.

Colombo, F., "Tiempo, aspecto y funciones comunicativas”, en Estudios de LingüísticaAplicada, núm. 15/ 16, 1992.

-, El Subsistema de los Tiempos Pasados de Indicativo en Español. Semántica y Sintaxis. México, UNAM, 2003.

COMriE, B., Aspect. Cambridge, Cambridge University Press, 1976.

Gutierrez Araus, M., "Formas temporales del pasado en indicativo", en Cuadernos de lengua española. Madrid, Arco Libros, 1997. 
HOPPER, P., "Aspect between discourse and grammar", en Hopper Paul, Tense and Aspect, vol 1. Amsterdam, J ohn Benjamins Publishing Company, 1979.

J URADO SALINAS, M., “La diferencia pretérito/ copretérito. Una explicación basada en los conceptos de ‘aspecto' y 'tipo de situaciones' y su aplicación a la enseñanza del español a extranjeros", en Decires, vol. 1, num. 1. México, UNAM, Centro de Enseñanza para Extranjeros, 1998.

LABOV, W., Language in the inner city: Studies in the Black English vernacular. Philadelphia, University of Pennsylvania, 1972.

MAINGUENEAU, D., Introducción a los métodos de análisis del discurso. Buenos Aires, Hachette, 1976.

MASLOV, Y., Contmstive Studies in Verbal Aspect. Heidel berg, J ulius Groos Verlag, 1985.

REINHART, T., "Principles of gestalt perception in the temporal organization of narrative texts", en Linguistics, num. 22, 1984, pp. 779-809.

SALABERRY, "The development of past tense verbal morphology in classroom L2 Spanish", en Applied Linguistics, num. 20, 1999, pp. 151-178.

SCHIFFRIN, D., Approaches to discourse. Oxford, Blackwell Publishers Inc., 1994.

WALLACE, S., "Figure and Ground. The interrelationships of linguistic categories", en Hopper, Tense and Aspect, vol. 1. Amsterdam, J ohn Benjamins Publishing Company, 1992.

WEINRICH, H., Estructura y función de los tiempos en el lenguaje. Madrid, Gredos, 1974. 